\title{
Sustainable nanocomposites based on halloysite nanotubes and pectin/polyethylene glycol blend
}

\author{
Giuseppe Cavallaro, Giuseppe Lazzara*, Stefana Milioto \\ Department of Physics and Chemistry, Università degli Studi di Palermo, Viale delle Scienze, Pad. 17, 90128 Palermo, Italy
}

\section{A R T I C L E I N F O}

\section{Article history:}

Received 25 July 2013

Received in revised form

6 September 2013

Accepted 15 September 2013

Available online 25 September 2013

\section{Keywords:}

Thermal stability

TGA

Halloysite

Nanocomposite

\begin{abstract}
A B S T R A C T
This study was focused on the preparation and characterization of biofilms based on pectin/polyethylene glycol 20000 (PEG) blend and halloysite nanotubes (HNTs). The obtained blends loaded with a natural nanoclay are proposed as sustainable alternative to the polymers produced from non-renewable resources such as fossil fuels. Properties of technological interest have been monitored and they were correlated to the structural features of the nanocomposites. It turned out that the wettability of the films can be tuned by changing the composition and the distribution of HNTs into the material as well as the surface roughness. The tensile properties of the blend are enhanced by the presence of the nanoclays. The PEG crystallinity is reduced by the nanoparticles and preserved if a certain amount of pectin is added.

This work represents a starting point to develop new green composite material, which can be used for purposes such as in packaging, by employing the strategy of adding plasticizers and fillers within a full biocompatible approach.
\end{abstract}

(c) 2013 Elsevier Ltd. All rights reserved.

\section{Introduction}

The largely used petroleum based plastics in several fields, such as in packaging, generates a relevant environmental impact in urban areas because of their non degradability. The disposal of plastic wastes by incineration produces an increase of carbon dioxide and, in some cases, toxic products which contribute to the global warming and the city pollution.

To the light of this situation, nowadays there is a growing interest on the development of biodegradable materials, sustainable alternative to the plastics produced from fossil fuel. Researchers have focused their attention on biopolymers and clay nanoparticles as renewable resources to process innovative green materials, such as polymer blends and bionanocomposites.

Pectin is a biodegradable polymer which is used to develop smart green materials useful for specific purposes. Blend based on pectin and chitosan may be used as carrier of pharmaceutical products [1]. Biofilms based on pectin and starch can be potentially employed in the food conservation because of their good mechanical properties [2] and oxygen barrier capability [3]. Gelatin-

\footnotetext{
* Corresponding author. Tel.: +39 3284279554

E-mail address: g.lazzara@unipa.it (G. Lazzara).
}

pectin films showed improved tensile characteristics and water resistance than the pristine polymers [4].

Polyethylene glycol (PEG) is a biocompatible, nontoxic polymer with good water solubility. It is an efficient plasticizer for biopolymers and nanocomposites. The mechanical properties of chitosan were improved by the addition of an appropriate amount of PEG $[5,6]$. The PEG content $\left(C_{\mathrm{PEG}}\right)$ is crucial to determine the effectiveness of the plasticization; a decrease of the glass transition temperature $\left(T_{\mathrm{g}}\right)$ of Poly(lactic acid) (PLA) was observed in polymer blends with $C_{\mathrm{PEG}}=20 \mathrm{wt} \%$ [7]. PLA/PEG blends with $C_{\mathrm{PEG}}$ up to $30 \mathrm{wt} \%$ showed a decrease of the elongation at the break point [8] and an increase of $T_{\mathrm{g}}[9]$ because of the phase separation of PEG in the composite system.

Filling a polymer blend with clay nanoparticles represents an alternative route to develop new nanomaterials with unique properties from the physico-chemical view point [10-12].

Among the clay nanoparticles, halloysite nanotubes (HNTs) are newly promising filler. The size of HNTs is rather polydisperse ranging between 0.1 and $2 \mu \mathrm{m}$ while the outer and inner diameters are ca. 30$50 \mathrm{~nm}$ and $1-30 \mathrm{~nm}$, respectively [13]. The biocompatibility of HNTs makes these nanoparticles appropriate to develop composite materials with appealing perspective in several applications, such as biotechnology [14-17], water decontamination [18,19], anticorrosive coatings $[20,21]$ and packaging $[22,23]$. Composite materials with humidity control ability were prepared by using HNTs as filler [24]. 

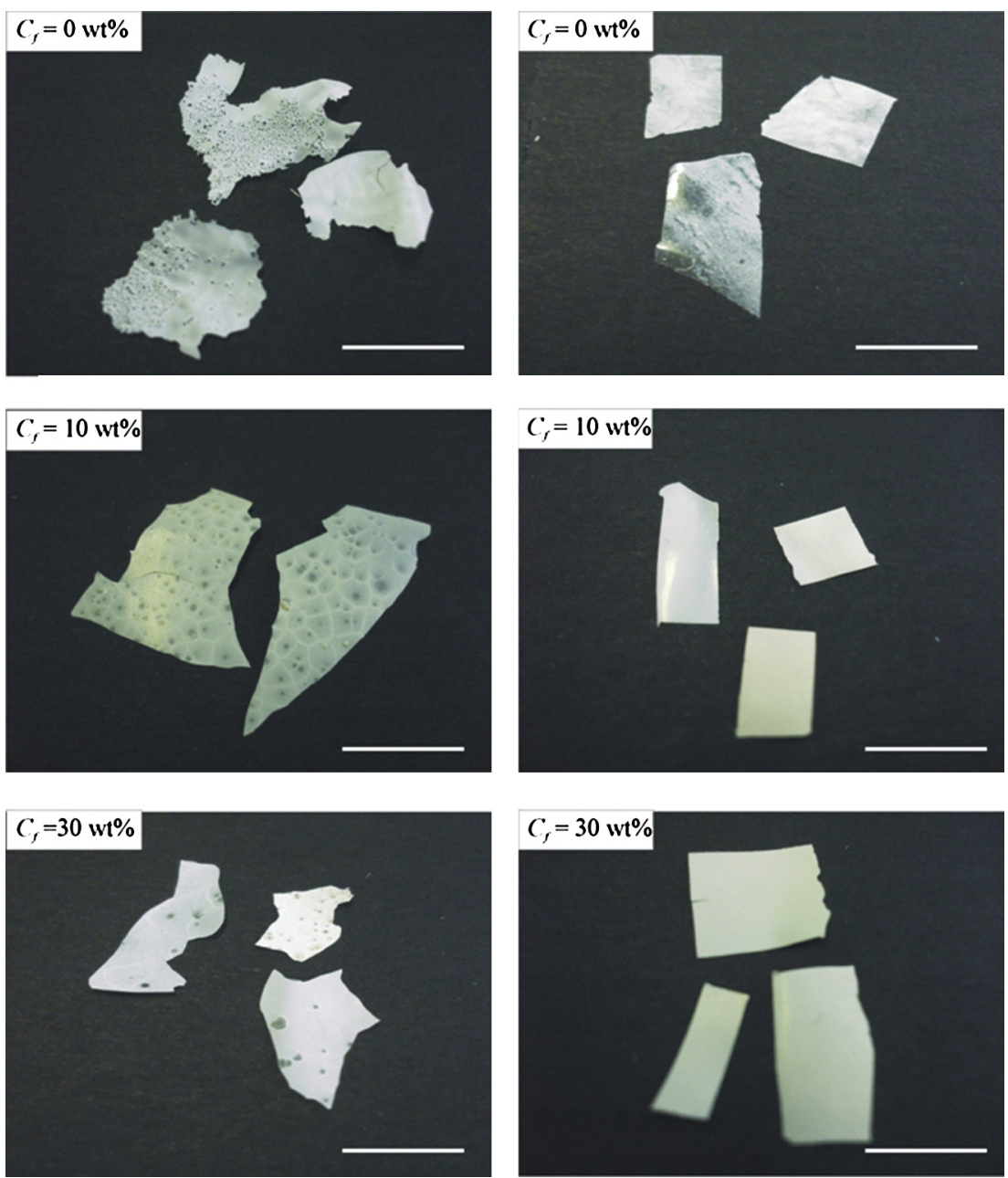

Fig. 1. Photos of bionanocomposites at variable $C_{\mathrm{f}}$ for $R_{\mathrm{pp}}=1$ (on the left) and $R_{\mathrm{pp}}=4$ (on the right). The bar is $10 \mathrm{~mm}$.

Literature reports that the addition of HNTs prevents the cracking in the drying latex films [25]. Filling pectins with HNTs caused an improvement of the thermal and the mechanical properties in a large clay loading regime. [23] The hydroxypropylcellulose/HNTs showed an enhancement of the polymer degradation temperature only for small nanoclay concentration, while the peculiar sandwich-like structure observed at the high filler loading caused a thermal destabilization [22]. It was observed [26] that PEG/HNTs is thermally more stable than the pristine polymer in the low filler regime where the nanomaterial presents a compact morphology, while the opposite thermal behavior occurred over the high HNTs loading region because of the more open structure.

Furthermore, it is known that the physical properties of blend polymers [27] and nanocomposites [26,28] depend on their supramolecular morphology that is controlled by the crystallization process in melt processing for crystalline and semicrystalline polymers. In many cases the nucleation and the overall crystallization may be enhanced by the presence of nanofillers which act as a nucleating agent [28]. Nevertheless, it was found that for plasticized PEG/PLA/cloisite nanocomposites [29] and for the PEG/halloysite nanotubes (HNTs) nanocomposites [26] the nanoclay did not play such a role.

In this work, we prepared blend films based on pectin and PEG 20000 as precursors of new plasticized bionanocomposites containing also HNTs. All biofilms were extensively investigated from the physico-chemical view point by determining the thermal and mechanical properties, the wettability and the water uptake behavior. The morphological study was crucial to explain the nanomaterial features.

The acquired knowledge represents a basic point for designing new hybrid sustainable materials.

\section{Experimental}

\subsection{Materials}

Pectin (degree of methyl esterification, 24\%, $\mathrm{Mw}=30-$ $\left.100 \mathrm{~kg} \mathrm{~mol}^{-1}\right)$, halloysite nanotubes $\left(\mathrm{Al}_{2} \mathrm{Si}_{2} \mathrm{O}_{5}(\mathrm{OH})_{4} \cdot 2 \mathrm{H}_{2} \mathrm{O}\right.$, HNTs are from Aldrich. Polyethylene glycol (PEG) $20,000 \mathrm{~g} \mathrm{~mol}^{-1}$ is from Fluka. All the materials were used without further purification. Water from reverse osmosis (Elga model Option 3) with a specific resistivity greater than $10^{5} \Omega$ m was used.

Table 1

The water contact angle at $\tau=0$ for pectin, PEG 20000 and the pectin/PEG 20000 blend $\left(R_{\mathrm{pp}}=4\right)$.

\begin{tabular}{ll}
\hline & $\theta_{i}\left({ }^{\circ}\right)$ \\
\hline Pectin $^{\mathrm{a}}$ & $75 \pm 1$ \\
PEG 20000 & $28 \pm 1$ \\
Pectin/PEG 20000 $\left(R_{\mathrm{pp}}=4\right)$ & $80 \pm 2$ \\
\hline
\end{tabular}

\footnotetext{
a From Ref. [22].
} 

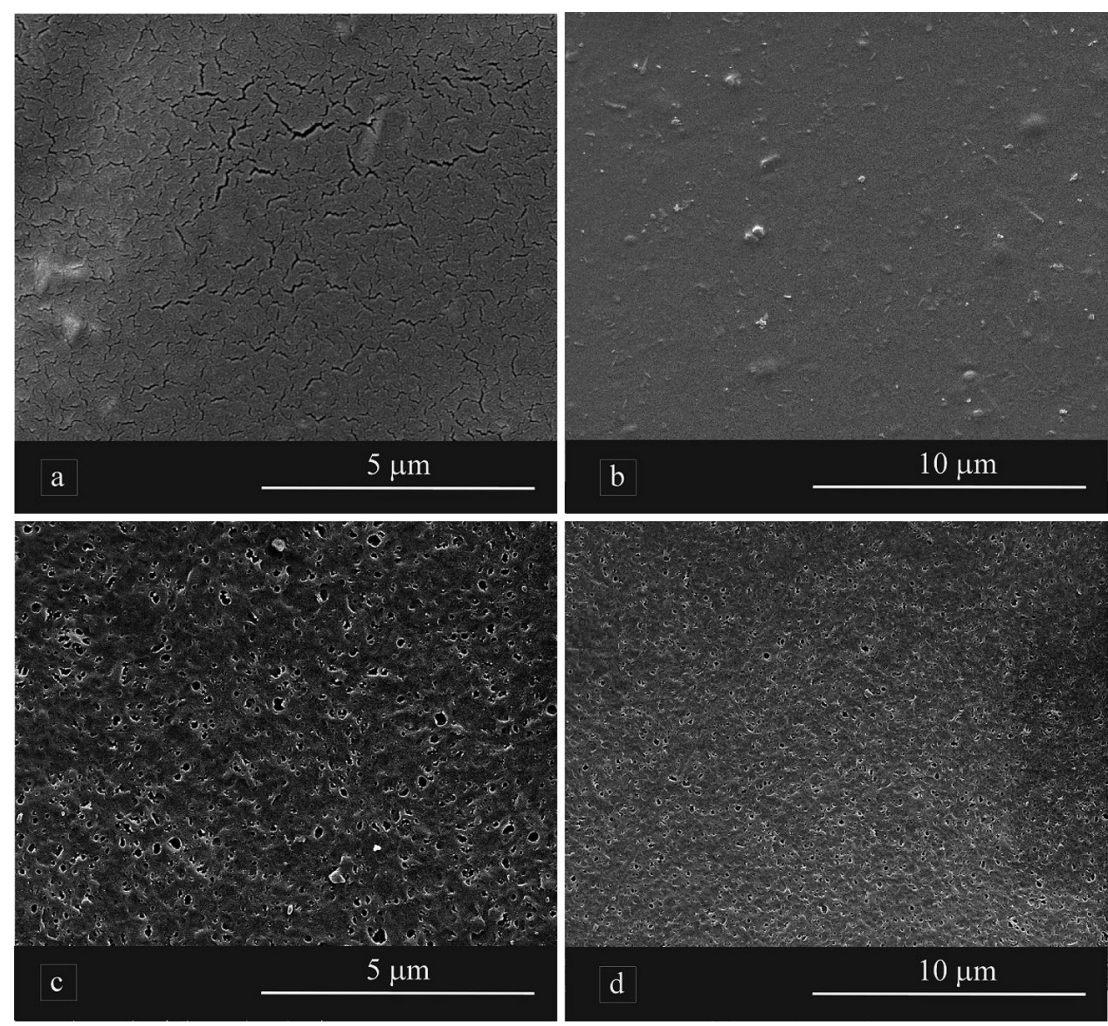

Fig. 2. Scanning electron microscopy images for surface of pristine pectin (a,b) and pectin/PEG 20000 blend with $R_{\mathrm{pp}}=4$ (c,d).

\subsection{Preparation of bionanocomposites}

We prepared a $2 \mathrm{wt} \%$ aqueous pectin solution under stirring at $70{ }^{\circ} \mathrm{C}$. Then, an appropriate amount of plasticizer (PEG 20000) and nanofiller (HNTs) were added to the pectin solution and kept under stirring over night. The well dispersed aqueous mixture was poured into glass Petri dishes under vacuum at $35{ }^{\circ} \mathrm{C}$ to evaporate water until weight was constant and to obtain biofilms with a thickness of ca. $60 \mu \mathrm{m}$. We selected the weight ratio pectin/PEG $20000\left(R_{\mathrm{pp}}\right)$ values of 1 and 4 . The composition of nanofiller $\left(C_{\mathrm{f}}\right)$ expressed as weight percent (grams of HNTs/100 $\mathrm{g}$ of plasticized nanocomposite) was systematically varied.

The prepared bionanocomposites evidenced clear macroscopic differences. As Fig. 1 shows, the nanomaterials with $R_{\mathrm{pp}}=1$ appear fragile and with several voids, while those with $R_{\mathrm{pp}}=4$ exhibit compact mechanical features.

\subsection{Methods}

\subsubsection{Contact angle measurements}

Contact angle studies were performed by means of an optical contact angle apparatus (OCA 20, Data Physics Instruments) equipped with a video measuring system having a high-resolution CCD camera and a high-performance digitizing adapter. SCA 20 software (Data Physics Instruments) was used for data acquisition. Rectangular $(5 \mathrm{~cm} \times 2 \mathrm{~cm})$ films were fixed on top of a plane solid support and kept flat throughout the analysis. The contact angle $(\theta)$ of water in air was measured by the sessile drop method by gently placing a droplet of $6 \pm 0.5 \mu \mathrm{L}$ onto the surface of the film. Temperature was set at $25.0 \pm 0.1^{\circ} \mathrm{C}$ for the support and the injecting syringe as well. Images were collected 25 times per second, starting from the deposition of the drop to $60 \mathrm{~s}$. The evolution of $\theta$, the volume $(V)$ and the surface area $(A)$ of droplet was monitored using a software-assisted image-processing procedure. A minimum of 5 droplets were examined for each film sample. Only the biofilms with $R_{\mathrm{pp}}=4$ were analyzed.

\subsubsection{Scanning electron microscopy}

The morphology of nanocomposites was studied using a microscope ESEM FEI QUANTA 200F. Before each experiment, the surface of the sample was coated with gold in argon by means of an Edwards Sputter Coater S150A to avoid charging under electron

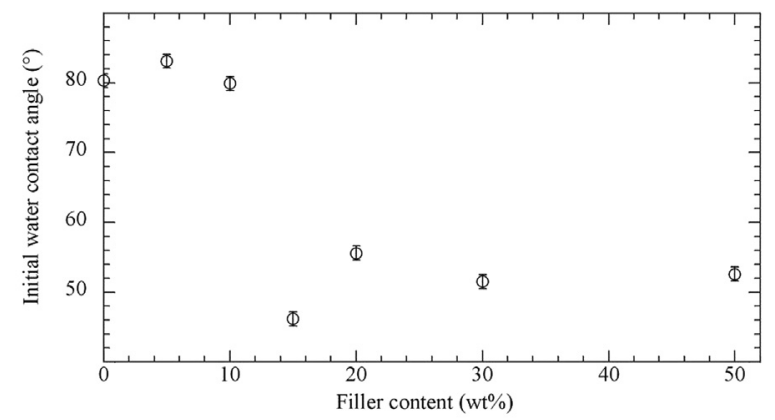

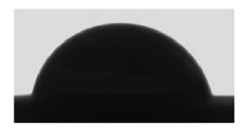

$0 \mathrm{wt} \%$

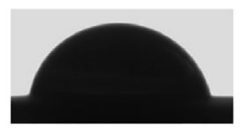

$10 \mathrm{wt} \%$

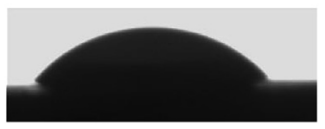

$50 \mathrm{wt} \%$
Fig. 3. Top: the water contact angle extrapolated at $\tau=0$ as a function of the filler content for bionanocomposites with $R_{\mathrm{pp}}=4$. Bottom: optical images of water drops just after the deposition on bionanocomposites with $R_{\mathrm{pp}}=4$ and variable filler content. 

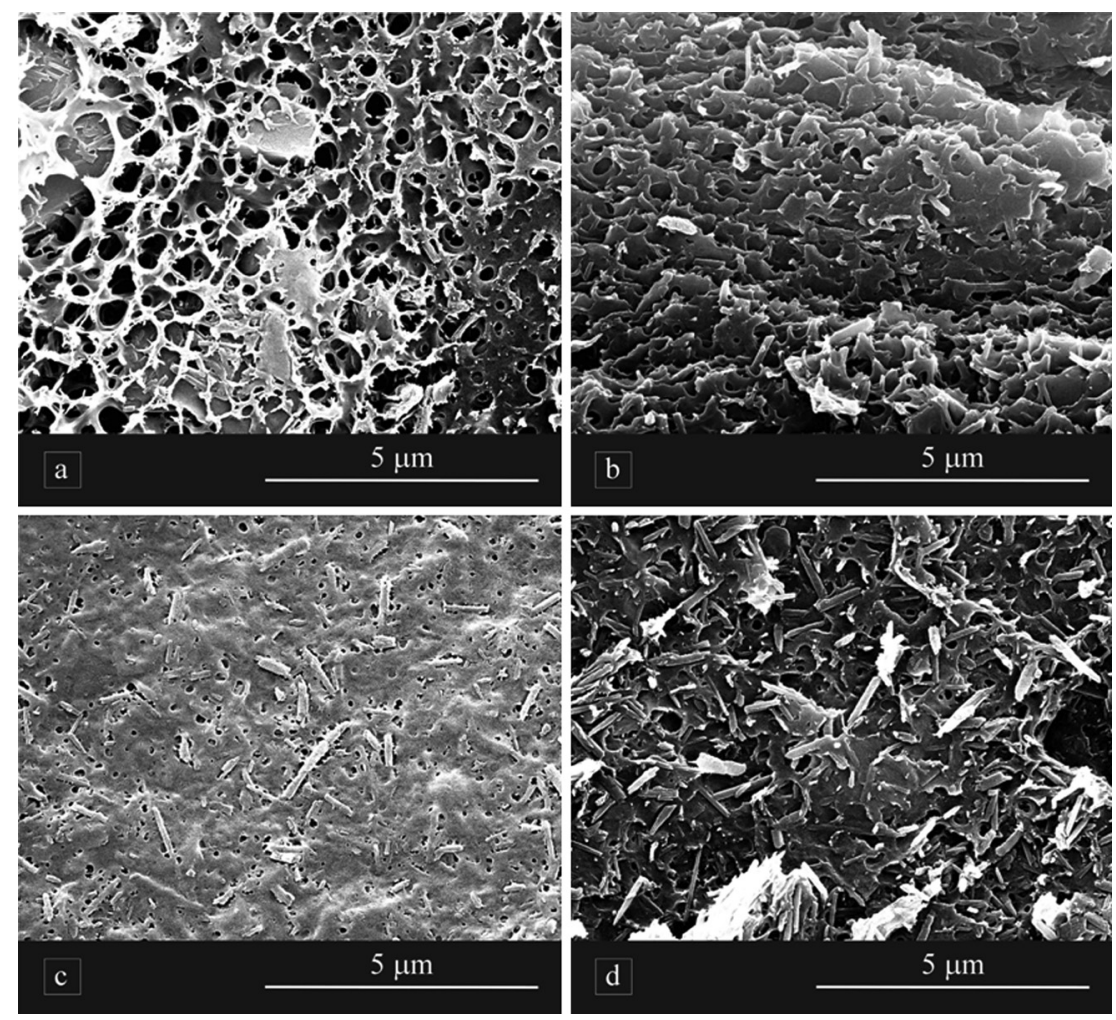

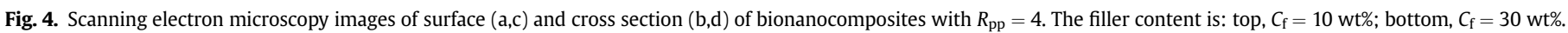

beam. The measurements were carried out in high vacuum mode $\left(<6 \times 10^{-4} \mathrm{~Pa}\right)$ for simultaneous secondary electron, the energy of the beam was $30 \mathrm{kV}$ and the working distance was $10 \mathrm{~mm}$. Minimal electron dose condition was set to avoid damage of the sample.

\subsubsection{Water uptake}

The water uptake (WU) experiments were done on the rectangular films with the same dimensions used for DMA measurements. The samples were supposed to be thin enough so that the molecular diffusion was considered to be one dimensional.

Samples were first dried under vacuum at $25^{\circ} \mathrm{C}$ for ca. $2 \mathrm{~h}$. After weighing, they were conditioned at certain relative humidity $(\mathrm{RH} \%)$ in a climate chamber. To obtain a stable equilibrium $R H \%$ of 33,75 and $97 \%$ saturated salt solutions of $\mathrm{MgCl}_{2}, \mathrm{NaCl}$ and $\mathrm{K}_{2} \mathrm{SO}_{4}$ were used. The temperature of the climate chamber was set at $25.0 \pm 0.5{ }^{\circ} \mathrm{C}$. The samples were removed after two weeks and weighed ( $\pm 0.00001 \mathrm{~g})$. The $W U \%$ of the films was calculated as follows:

$W U \%=100 \times\left(M_{t}-M_{0}\right) / M_{t}$

where $M_{0}$ and $M_{\mathrm{t}}$ are the weights of the sample before and after two weeks exposure to a certain $R H \%$, respectively.

\subsubsection{Tensile properties}

Tensile properties were determined by means of DMA Q800 instrument (TA Instruments). For all mechanical measurements, the samples were films of rectangular shape $(10.00 \mathrm{~mm} \times 6.00 \mathrm{~mm} \times 0.060 \mathrm{~mm})$. Tensile tests were performed with a stress ramp of $1 \mathrm{MPa} \min ^{-1}$ at $26.0 \pm 0.5^{\circ} \mathrm{C}$. We determined the values of the elastic modulus $(E)$, the tensile strength (defined as the tensile stress at which the material fractures $\left(\sigma_{\mathrm{r}}\right)$ ) and the percent elongation at break $(\varepsilon \%)$. Each nanocomposite was measured five times and the average values are reported.
The characteristics of the bionanocomposites with $R_{\mathrm{pp}}=1 \mathrm{did}$ not allow us to perform tensile experiments (Fig. 1).

\subsubsection{Thermogravimetry}

The experiments were performed by means of a Q5000 IR apparatus (TA Instruments) under the nitrogen flow of $25 \mathrm{~cm}^{3} \mathrm{~min}^{-1}$ for the sample and $10 \mathrm{~cm}^{3} \mathrm{~min}^{-1}$ for the balance. The weight of each sample was ca. $10 \mathrm{mg}$. The calibration was carried out by means of Curie temperature of standards (nickel, cobalt and their alloys). The measurements were conducted by heating the sample from room temperature to $900{ }^{\circ} \mathrm{C}$ with a rate of $10^{\circ} \mathrm{C} \mathrm{min}^{-1}$. The degradation temperature of pectin $\left(T_{d 1}\right)$ and PEG $20000\left(T_{d 2}\right)$ were taken at the maximums of the first order derivative curves of mass loss to temperature (DTG curves). Examples of DTG curves are reported in the ESI.

The thermal degradation of pectin (ca. $240{ }^{\circ} \mathrm{C}$ ) and PEG 20000 $\left(390{ }^{\circ} \mathrm{C}\right.$ ) are well resolved in all bionanocomposites. The materials with very high HNTs content clearly showed a DTG peak at ca. $490{ }^{\circ} \mathrm{C}$ due to the expulsion of the two water molecules from the nanoclay interlayer. At very large $C_{\mathrm{f}}$, DTG curve exhibited (see ESI) a peak at ca. $180^{\circ} \mathrm{C}$ and a shoulder at ca. $340{ }^{\circ} \mathrm{C}$, which are probably correlated to PEG 20000 thermal degradation.

Table 2

Water uptake values at different relative humidity.

\begin{tabular}{lcc}
\hline WU\% $(R h=33 \%)$ & WU\% $(R h=75 \%)$ & WU\% $(R h=97 \%)$ \\
\hline Pectin & & \\
$3.6 \pm 0.7$ & $8.2 \pm 0.8$ & $14 \pm 2$ \\
Pectin/PEG $20000\left(R_{\mathrm{pp}}=4\right)$ & $5.0 \pm 0.9$ & $8 \pm 1$ \\
$1.3 \pm 0.3$ & $\left.4 . C_{\mathrm{f}}=50.52\right)$ & $7 \pm 1$ \\
Pectin/PEG 20000/HNTs $\left(R_{\mathrm{pp}}=0.8\right.$ & $4.7 \pm 0.1$ \\
$1.3 \pm 0.0$
\end{tabular}




\subsubsection{Differential scanning calorimetry}

The differential scanning calorimeter TA Instrument 2920 CE was used under nitrogen flow atmosphere (flow rate $=60 \mathrm{~cm}^{3} \mathrm{~min}^{-1}$ ). The apparatus was calibrated with indium. The used pans are in aluminum and contain ca. $5 \mathrm{mg}$ of the compound. The enthalpy $\left(\Delta H_{\mathrm{m}}\right)$ and the temperature $\left(T_{\mathrm{m}}\right)$ of melting for PEG 20000 were determined by the experiments performed in the range $0-90{ }^{\circ} \mathrm{C}$ with a heating rate of $10^{\circ} \mathrm{C} \mathrm{min}^{-1}$. The $T_{\mathrm{m}}$ and $\Delta H_{\mathrm{m}}$ values were defined as the onset and the area of the melting endothermic peak, respectively. The $\Delta H_{\mathrm{m}}$ values were calculated per gram of PEG 20000 in the composite material. Moreover, we studied the kinetics of crystallization process of PEG 20000 under non-isothermal conditions by changing the cooling rate. To this aim, the sample was heated to $90{ }^{\circ} \mathrm{C}$ and kept for $10 \mathrm{~min}$ to eliminate any previous thermal history; then, it was cooled down to $0{ }^{\circ} \mathrm{C}$ at $2.5,5,10$ and $15^{\circ} \mathrm{C} \mathrm{min}^{-1}$.

\section{Results and discussion}

\subsection{Morphology, wettability and water uptake of bionanomaterials}

The wettability of pectin/PEG blend film $\left(R_{\mathrm{pp}}=4\right)$ and the corresponding bionanocomposites at variable $C_{\mathrm{f}}$ was determined.

For all biofilms, both $V$ and $\theta$ decrease with time $(\tau)$ while $A$ increases (see ESI). These values indicate that both spreading and water absorption occur during the measurements as reported for several biopolymers [30] and bionanocomposites based on pectin [22]. Farris et al. [30] analyzed the $\theta$ vs $\tau$ trends with an exponential function to extrapolate the $\theta$ value at $\tau=0 \mathrm{~s}\left(\theta_{i}\right)$. Examples of the best fits are given in ESI. We observed that the PEG 20000 addition caused a small but significant increase (ca. $5^{\circ}$ ) of $\theta_{i}$ despite the PEG 20000 hydrophilic nature (Table 1 ). Hydrophobic surfaces can be formed by hydrophilic substances if the roughness of the surface is enhanced [31]. For composite materials, the presence of an hydrophilic additive into a matrix can generate an increase of $\theta_{i}$ because the surface composition is modified [22]. To the light of these insights the peculiar effect generated by PEG 20000 on the wettability of the biomaterial is ascribable to the increase of the surface roughness. This hypothesis is confirmed by SEM images (Fig. 2) showing that the surface of the pectin/PEG 20000 blend is very rough with many craters (size of ca. $2 \mu \mathrm{m}$ ), while the pectin surface is smooth.

More intriguing appears the wettability of the bionanocomposites. The general trend of $\theta_{i}$ vs $C_{\mathrm{f}}$ (Fig. 3 ) shows that over the low filler loading regime $\left(C_{\mathrm{f}} \leq 10 \mathrm{wt} \%\right), \theta_{i}$ is nearly equal to that of the blend; for $C_{\mathrm{f}}>10 \mathrm{wt} \% \theta_{i}$ sharply decreases in agreement with the enhancement of the surface hydrophilicity. Such a phenomenon is straightforwardly evidenced by the drop images collected after just the deposition (Fig. 3). These results can be univocally understood in the light of the morphological study (Figs. 4 and 5) by taking into account the factors influencing the surface properties: 1) the roughness; and 2) the population of HNTs at the interface. Fig. 4 shows that for $C_{\mathrm{f}}=10 \mathrm{wt} \%$, the surface of bionanocomposite is still rough, with the presence of craters (size of ca. $2 \mu \mathrm{m}$ ), burying the HNTs. The SEM micrography of the transverse section shows that the filler is confined along the edges of the biofilm. For $C_{\mathrm{f}}=30 \mathrm{wt} \%$ the surface roughness appears decreased and the HNTs are homogeneously dispersed on the surface as well as along the edges. Thus, the strong decrease of $\theta_{i}$ observed over the HNTs high loading region is explained by both the enrichment of the nanoclay at the interface and the reduction of the roughness because these morphological changes simultaneously contribute to enhance the surface hydrophilicity of the biofilms.

To the surface properties is correlated the tendency of the materials to incorporate water from environmental moisture that is of relevant interest for applicative purposes of biopolymers [32-34]; with this in mind, water uptake experiments were performed on the blend and the bionanocomposite film with $R_{\mathrm{pp}}=4$ and after
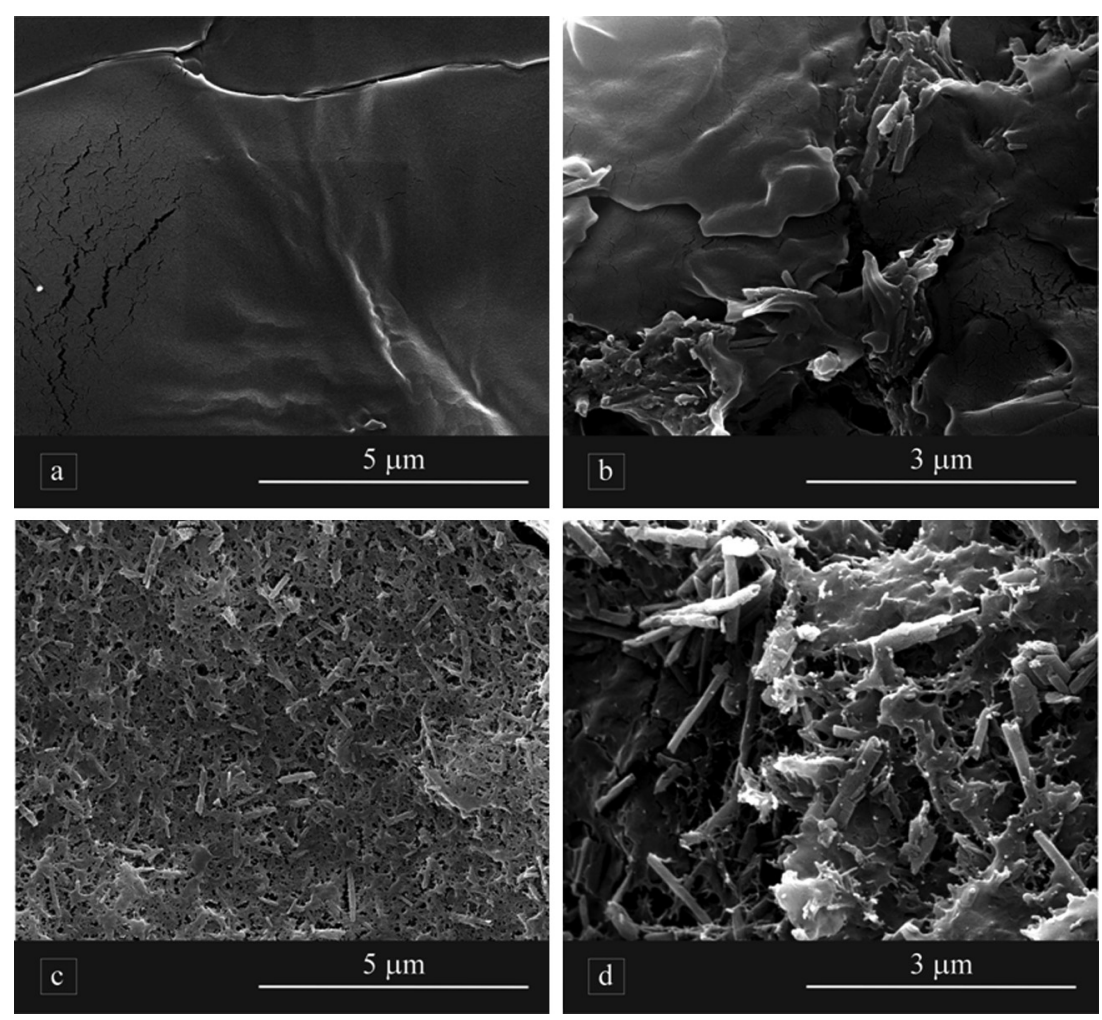

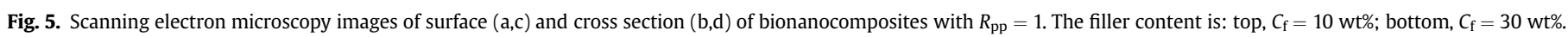




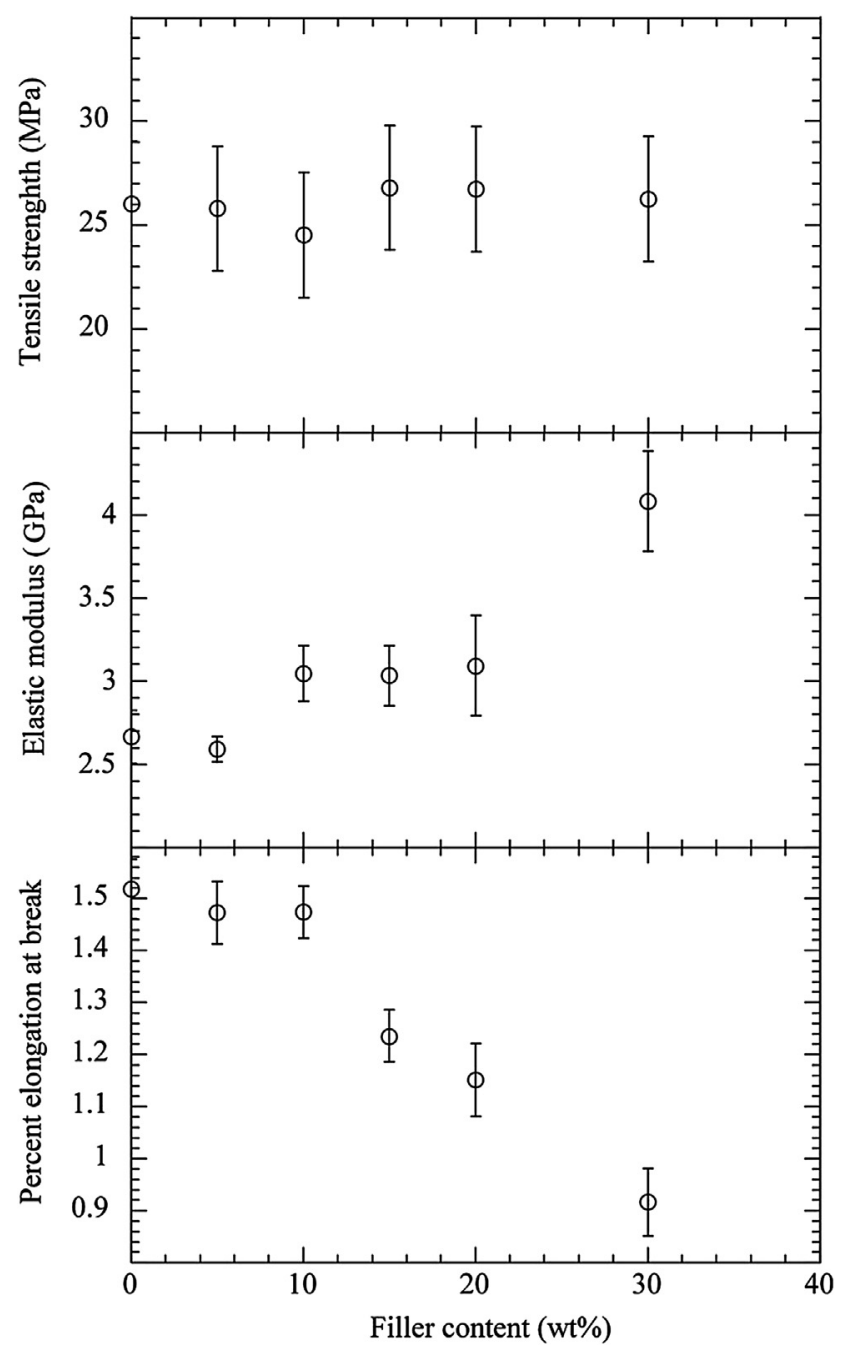

Fig. 6. Tensile properties of bionanocomposites with $R_{\mathrm{pp}}=4$ as function of filler content.

conditioning at variable $\mathrm{RH} \%$ (Table 2). We observed that the WU\% values of the pectin/PEG 20000 blend are lower than those for the pectin. The addition of large amount of HNTs to the blend generated biomaterials with unaltered WU\% in spite of the hydrophilic nature of the nanoclay that is promising for applications in several field such as coatings for food conservation.

\subsection{Tensile properties of bionanocomposites}

The plasticization of pectin with PEG 20000 changed the tensile properties of the biopolymer. A similar result was also observed for chitosan/PEG 20000 blends [6]. The addition of PEG 20000 $\left(R_{\mathrm{pp}}=4\right)$ generated a slight improvement of $E(\mathrm{ca} .10 \%)$ with respect to the pristine polymer [23], while both $\sigma_{\mathrm{r}}$ and $\varepsilon \%$ decreased.

The effect of HNTs on the tensile properties of the blend pectin/ PEG $20000\left(R_{\mathrm{pp}}=4\right)$ films was investigated. Some examples of the stress-strain curves for plasticized bionanocomposites at variable $C_{\mathrm{f}}$ are reported in the ESI. The $E$ increase upon HNTs addition (Fig. 6) is a clear indication of the good dispersion of the filler into the polymer matrix as reported for other plasticizes polymer/clay composites [35-38]. In fact, the uniform distribution of HNTs into the nanocomposite enhances the affinity and the adhesion of the polymers to the filler surface. The highest $E$ value was observed for $C_{\mathrm{f}}=30 \mathrm{wt} \%$ (the increase was of $50 \%$ respect to the blend film pectin/PEG $20000\left(R_{\mathrm{pp}}=4\right)$ and of ca. $75 \%$ respect to the pristine pectin) [23].

The tensile strength is not influenced by the nanoclay while $\varepsilon \%$ decreases with $C_{\mathrm{f}}$ as reported in literature for starch/poly vinyl alcohol/Montmorillonite nanocomposites [35]. The latter finding was explained in terms of clay-polymer interactions that avoid the sliding of polymer chains against each other.

Finally, bionanocomposites with $R_{\mathrm{pp}}=1$ were not studied by DMA because of their high fragility. Such a loss mechanical strength is consistent with the morphology at the mesoscopic scale. In fact, for $C_{\mathrm{f}}=30 \mathrm{wt} \%$ and $R_{\mathrm{pp}}=1$ a phase separation and a formation of globules (size of ca. $10 \mu \mathrm{m}$ ) take place at the interface generating an inhomogeneous and fractured surface (Fig. 7). For the sample at $C_{\mathrm{f}}=30 \mathrm{wt} \%$ and $R_{\mathrm{pp}}=4$, HNTs are uniformly dispersed at the surface that appears rather compact (Fig. 7).

\subsection{Thermal characterization of bionanomaterials}

The thermal degradation and crystallization behavior of the materials were also determined. Both $T_{d 1}$ and $T_{d 2}$ in the pectin/PEG 20000 blends have similar values to those of the pristine polymers. Fig. 8 reports the effect of the filler on the degradation temperatures of both polymers for bionanocomposites. $T_{d 1}$ increases in the presence of HNTs with a larger slope for $R_{\mathrm{pp}}=4$. This finding corroborates with the reports [23] that the HNT lumen can encapsulate the pectin degradation products delaying the mass transport. Of course, such a phenomenon is enhanced by increasing the pectin concentration. Furthermore, the thermal stabilization of the biopolymer agrees with the good dispersion of the filler into the polymeric matrix [39-41]. The degradation of pectin $\left(T_{d 1}<T_{d 2}\right)$
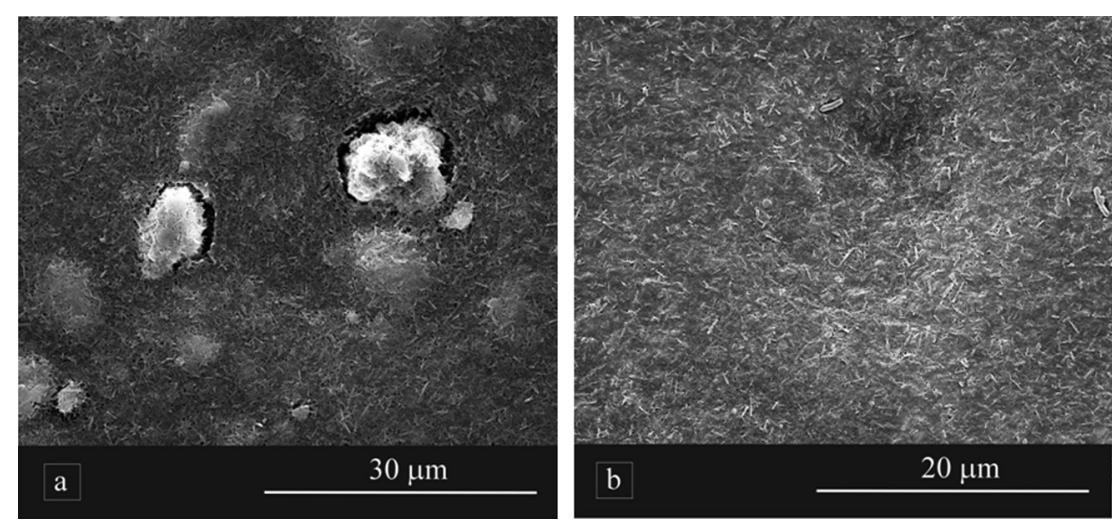

Fig. 7. Scanning electron microscopy images of bionanocomposites at $C_{\mathrm{f}}=30$ wt $\%$ with $R_{\mathrm{pp}}=1$ (a) and 4 (b). 


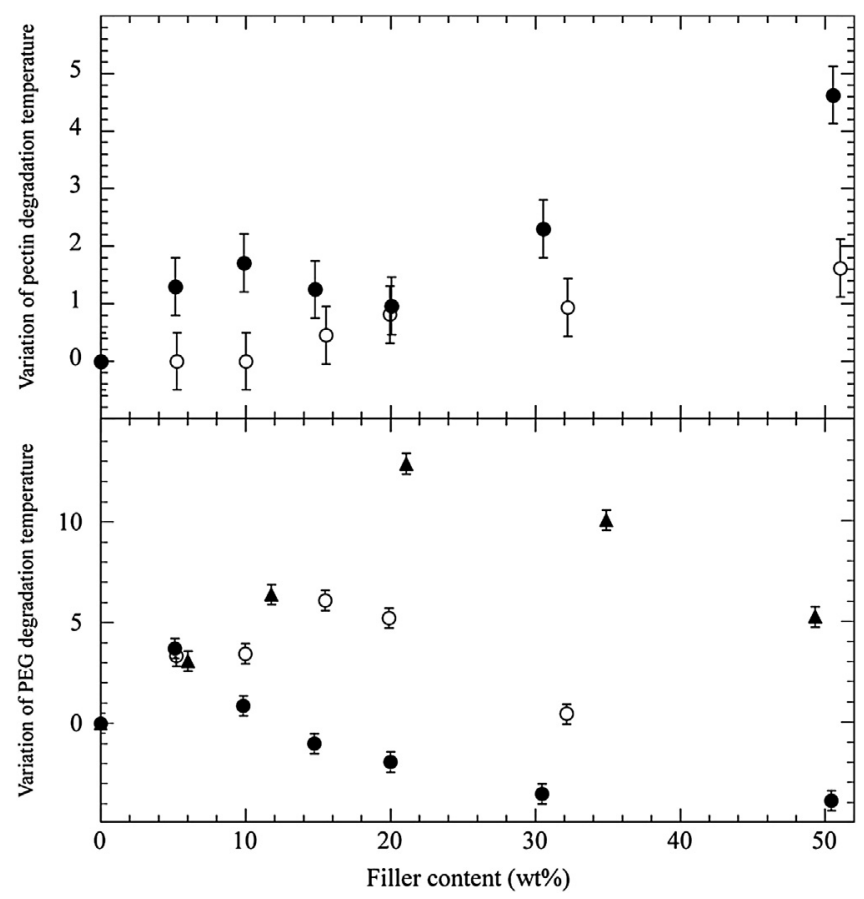

Fig. 8. Variation of the degradation temperature of the pectin (top) and PEG 20000 (bottom) as function of the filler content for bionanocomposites with $R_{\mathrm{pp}}=0(\boldsymbol{\Lambda})$, $R_{\mathrm{pp}}=1(\bigcirc)$ and $R_{\mathrm{pp}}=4(\bullet)$. Data at $R_{\mathrm{pp}}=0$ are from Ref. [26].

influences the thermal stability of PEG 20000. As Fig. 8 illustrates, while the $T_{d 2}$ vs $C_{\mathrm{f}}$ profile remains unchanged, the maximum is shifted towards lower values upon the pectin addition. The PEG 20000 thermal destabilization generated by the pectin proves that the HNTs hollows are no more available to incorporate the PEG 20000 degradation products.

The crystallinity of the blend may derive from PEG 20000 having a certain degree of crystallinity. Such a property was evaluated by studying the melting process through the DSC. The $\Delta H_{\mathrm{m}}$ values (Table 3 ) of the blends indicate that the interactions with the pectin reduce the crystallinity fraction of the PEG 20000. This effect is more important with the $R_{\mathrm{pp}}$ increase. Literature reports that the addition of electrolytes to the PEGs generate a decrease of the polymer crystallinity [42].

The addition of HNTs to the blends essentially did not modify the crystallinity of PEG 20000 as the $\Delta H_{\mathrm{m}}$ and $T_{\mathrm{m}}$ values of all the bionanocomposites show (Fig. 9). It was demonstrated that the interactions between PEG 20000 and HNTs reduce the polymer crystallinity [26] so that one may conclude that competitive processes of HNTs/pectin and HNTs/PEG 20000 interactions take place and that the interactions of pectin with the nanoclay surface appears privileged. The crystallization process of PEG 20000 was studied under non-isothermal conditions. The crystallization temperature $\left(T_{\mathrm{c}}\right)$ for all of the nanocomposites decreased linearly with the cooling rate (see Figure in ESI). The $T_{\mathrm{c}}$ values extrapolated at

Table 3

Temperature and enthalpy of PEG 20000 for pectin/PEG 20000 blends and pristine PEG 20000.

\begin{tabular}{lcl}
\hline & $\Delta H_{\mathrm{m}}\left(\mathrm{J} \mathrm{g}^{-1}\right)$ & $T_{\mathrm{m}}\left({ }^{\circ} \mathrm{C}\right)$ \\
\hline Pectin/PEG $20000\left(R_{\mathrm{pp}}=1\right)$ & 168.4 & 62.8 \\
Pectin/PEG $20000\left(R_{\mathrm{pp}}=4\right)$ & 50.5 & 59.8 \\
PEG 20000 & $199.4^{\mathrm{a}}$ & $60.8^{\mathrm{a}}$ \\
\hline
\end{tabular}

\footnotetext{
${ }^{a}$ From Ref. [26].
}

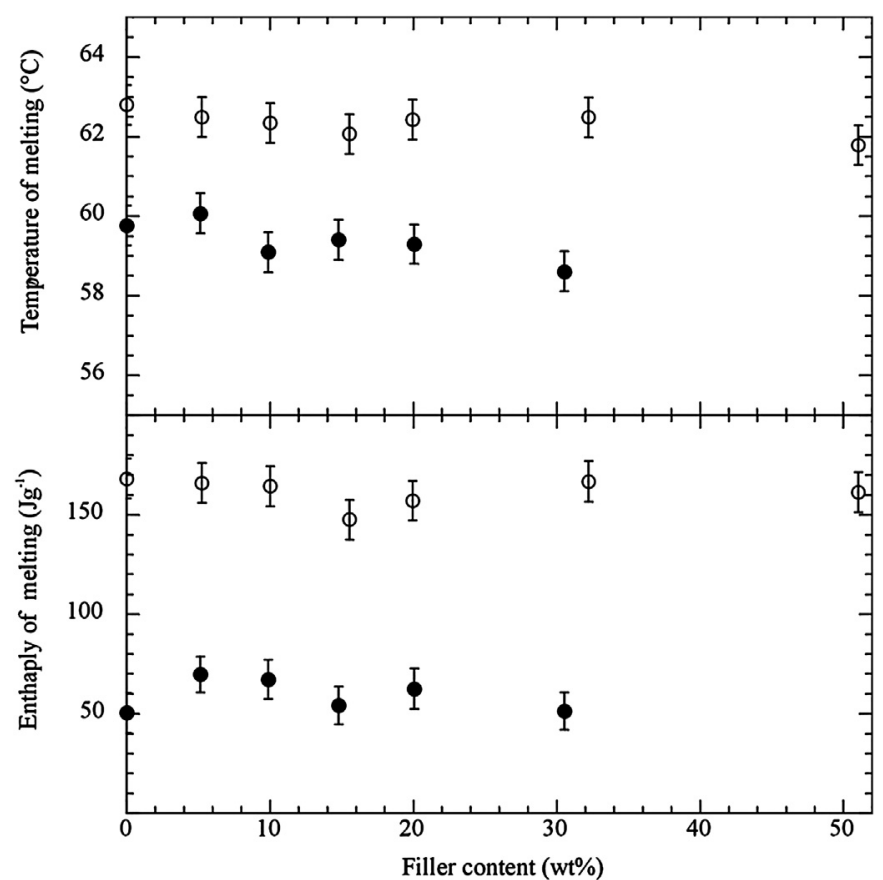

Fig. 9. Temperature (top) and enthalpy (bottom) of PEG 20000 melting as function of the filler content for bionanocomposites with $R_{\mathrm{pp}}=1(\bigcirc)$ and $R_{\mathrm{pp}}=4(\mathbf{O})$.

null heating rates are reported as functions of the nanofiller amount (Fig. 10). It has to be noted that the nanotubes did not influence the crystallization temperature of PEG 20000 in the presence of pectin while the opposite occurs if HNTs/PEG 20000 is considered [26]. Therefore, one can conclude that the pectin protects the nanoparticles and the melting and crystallization properties of PEG 20000 in the blend nanocomposites are preserved.

\section{Conclusions}

We prepared biofilms based on pectin/PEG 20000 blend filled with inorganic natural nanoparticles. Halloysite nanotubes (HNTs) are very promising in material science because, besides the interesting properties conferred by the peculiar hollow tubular shape, they are largely available and at low cost. The obtained nanocomposite blends represents a sustainable alternative to the plastic materials synthesized from fossil fuels. The structural features are tunable and therefore a variety of materials with controlled properties were obtained. A comprehensive characterization of the

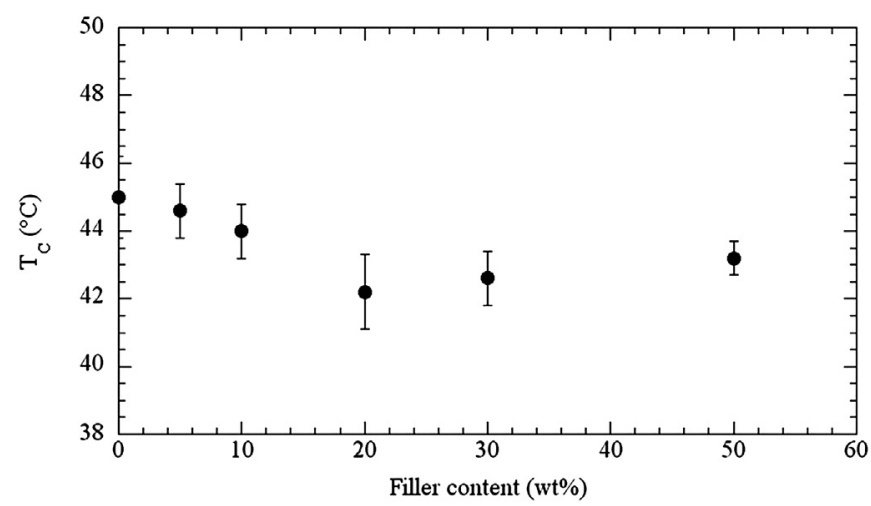

Fig. 10. PEG 20000 crystallization temperature at null cooling rate for Pectin/PEG 20000/HNTs bionanocomposites at $R_{\mathrm{pp}}=1$. 
materials was carried out through wettability, water uptake, crystallinity, thermal degradation and tensile properties, which were correlated to the mesoscopic structure.

With this study we successfully propose to employ the strategy widely used for polymeric materials, such as the addition of plasticizers and inorganic fillers, with a green biocompatible approach.

\section{Acknowledgments}

The work was financially supported by the University of Palermo, PRIN 2010-2011 (prot. 2010329WPF) and FIRB 2012 (prot. RBFR12ETL5).

\section{Appendix A. Supplementary data}

Supplementary data related to this article can be found online at http://dx.doi.org/10.1016/j.polymdegradstab.2013.09.012.

\section{References}

[1] Ghaffari A, Navaee K, Oskoui M, Bayati K, Rafiee-Tehrani M. Eur J Pharm Biopharm 2007;67:175-86.

[2] Coffin DR, Fishman ML, Ly TV. J Appl Polym Sci 1996;61:71-9.

[3] Coffin DR, Fishman ML. J Appl Polym Sci 1994;54:1311-20.

[4] Farris S, Schaich KM, Liu L, Cooke PH, Piergiovanni L, Yam KL. Food Hydrocoll 2011;25:61-70.

[5] Wang Q, Dong Z, Du Y, Kennedy JF. Carbohydr Polym 2007;69:336-43.

[6] Gunbas ID, Aydemir Sezer U, Gülce İz S, Deliloğlu Gürhan İ, Hasirci N. Ind Eng Chem Res 2012;51:11946-54.

[7] Ozkoc G, Kemaloglu S. J Appl Polym Sci 2009;114:2481-7.

[8] Hu Y, Hu YS, Topolkaraev V, Hiltner A, Baer E. Polymer 2003;44:5711-20.

[9] Ljungberg N, Wesslén B. Polymer 2003;44:7679-88.

[10] Tharanathan RN. Trends Food Sci Technol 2003;14:71-8.

[11] Alcantara ACS, Aranda P, Darder M, Ruiz-Hitzky E. J Mater Chem 2010;20: 9495-504.

[12] Ruiz-Hitzky E, Aranda P, Darder M, Fernandes FM. In: Bergaya Faïza, Lagaly Gerhard, editors. Developments in clay science, vol. 5. Elsevier; 2013. p. $721-41$.
[13] Lvov YM, Shchukin DG, Mohwald H, Price RR. ACS Nano 2008;2:814-20.

[14] Yah WO, Xu H, Soejima H, Ma W, Lvov Y, Takahara A. J Am Chem Soc 2012;134:12134-7.

[15] Yah WO, Takahara A, Lvov YM. J Am Chem Soc 2011;134:1853-9.

[16] Vergaro V, Abdullayev E, Lvov YM, Zeitoun A, Cingolani R, Rinaldi R, et al. Biomacromolecules 2010;11:820-6.

[17] Liu M, Wu C, Jiao Y, Xiong S, Zhou C. J Mater Chem B 2013;1:2078-89.

[18] Cavallaro G, Gianguzza A, Lazzara G, Milioto S, Piazzese D. Appl Clay Sci 2013;72:132-7.

[19] Cavallaro G, Lazzara G, Milioto S. J Phys Chem C 2012;116:21932-8.

[20] Abdullayev E, Price R, Shchukin D, Lvov Y. ACS Appl Mater Interfaces 2009; 1 ; 1437-43.

[21] Abdullayev E, Lvov Y. J Mater Chem 2010;20:6681-7.

[22] Cavallaro G, Donato DI, Lazzara G, Milioto S. J Phys Chem C 2011;115: 20491-8.

[23] Cavallaro G, Lazzara G, Milioto S. Langmuir 2011;27:1158-67.

[24] Dong F, Wang J, Wang Y, Ren S. J Mater Chem 2012;22:11093-100.

[25] Qiao J, Adams J, Johannsmann D. Langmuir 2012;28:8674-80.

[26] Cavallaro G, Lisi R, Lazzara G, Milioto S. J Therm Anal Calorim 2013;112: 383-9.

[27] He Y, Fan Z, Hu Y, Wu T, Wei J, Li S. Eur Polym J 2007;43:4431-9.

[28] Durmus A, Ercan N, Soyubol G, Deligöz H, Kaşgöz A. Polym Compos 2010;31: 1056-66.

[29] Gumus S, Ozkoc G, Aytac A. J Appl Polym Sci 2012;123:2837-48.

[30] Farris S, Introzzi L, Biagioni P, Holz T, Schiraldi A, Piergiovanni L. Langmuir 2011;27:7563-74.

[31] Marmur A. Langmuir 2008;24:7573-9.

[32] Kučerík J, Prúšová A, Rotaru A, Flimel K, Janeček J, Conte P. Thermochim Acta 2011;523:245-9.

[33] Mlčoch T, Kučerík J. J Therm Anal Calorim 2013:1-9.

[34] Prưšová A, Šmejkalová D, Chytil M, Velebný V, Kučerík J. Carbohydr Polym 2010;82:498-503.

[35] Tang X, Alavi S. J Agric Food Chem 2012;60:1954-62.

[36] Ali SS, Tang X, Alavi S, Faubion J. J Agric Food Chem 2011;59:12384-95.

[37] Chivrac F, Pollet E, Dole P, Avérous L. Carbohydr Polym 2010;79:941-7.

[38] Lee J-H, Jung D, Hong C-E, Rhee KY, Advani SG. Compos Sci Technol 2005;65: $1996-2002$.

[39] Lecouvet B, Gutierrez JG, Sclavons M, Bailly C. Polym Degrad Stab 2011;96: $226-35$.

[40] Blanco I, Cicala G, Latteri A, Mamo A, Recca A. J Therm Anal Calorim 2013;112: $375-81$.

[41] Blanco I, Bottino FA. Polym Compos 2013;34:225-32.

[42] Singh T, Bhat SV. Bull Mater Sci 2003;26:707-14. 